\title{
Vitamin K Antagonist Use and Fracture
}

\author{
Wallis C. Y. Lau, PhD ${ }^{1,2}$, Kenneth K. C. Man, MPH', and lan C. K. Wong, PhD ${ }^{1,2}$
}

'Research Department of Practice and Policy, UCL School of Pharmacy, London, UK; ${ }^{2}$ Centre for Safe Medication and Practice Research, Department of Pharmacology and Pharmacy, Li Ka Shing Faculty of Medicine, The University of Hong Kong, Pok Fu Lam, Hong Kong.

J Gen Intern Med 35(1):396-7

DOI: $10.1007 / \mathrm{s} 11606-019-05185-2$

(C) Society of General Internal Medicine 2019

$\mathrm{W}$ e read with interest the article by Fiordellisi and colleagues, who reported findings of a systematic review and meta-analysis on the association between vitamin $\mathrm{K}$ antagonist (VKA) use and fracture. ${ }^{1}$ The results provide an important contribution to better understand the risk of fractures associated with VKA use, which is still controversial and not well described in clinical practice.

One of the key findings of Fiordellisi et al. was that there was no association between a higher risk of fracture and the use of VKA versus non-vitamin $\mathrm{K}$ antagonist oral anticoagulant (NOAC). The finding was supported by a pooled estimate of 0.95 (95\% confidence interval $0.78-1.15$ ) with respect to $V K A$ versus $N O A C$ users. In reviewing this finding, we looked at the data presented in the forest plot (Figure 3 in the article). We found that the data for three of the included studies: Lucenteforte et al., ${ }^{2}$ Norby et al., ${ }^{3}$ and Steffel et al., ${ }^{4}$ matched with the adjusted hazard ratios of NOAC versus VKA users reported in these studies (Lucenteforte: dabigatran versus warfarin; Norby: rivaroxaban versus warfarin; Steffel: edoxaban

Table 1 Pooled Results for Vitamin K Antagonists (VKAs) Versus Non-vitamin K Antagonist Oral Anticoagulant (NOAC) When the Inverse of the Original Result Estimates Are Used in the Metaanalysis

\begin{tabular}{|c|c|c|c|c|}
\hline $\begin{array}{l}\text { Study or } \\
\text { subgroup }\end{array}$ & $\begin{array}{l}\text { Log } \\
\text { [result } \\
\text { estimates] }\end{array}$ & $\mathrm{SE}$ & $\begin{array}{l}\text { Weight } \\
(\%)\end{array}$ & $\begin{array}{l}\text { Result } \\
\text { estimates } \\
\text { IV, random, } \\
\text { 95\% CI }\end{array}$ \\
\hline Lau 2017 & 0.414 & 0.214 & 7.0 & $\begin{array}{l}1.51[0.99, \\
2.30]\end{array}$ \\
\hline $\begin{array}{l}\text { Lucenteforte } \\
2017\end{array}$ & 0.039 & 0.272 & 4.3 & $\begin{array}{l}1.04[0.61, \\
1.77]^{\mathrm{I}}\end{array}$ \\
\hline Norby 2017 & 0.182 & 0.088 & 41.5 & $\begin{array}{l}1.20[1.01, \\
1.43]^{\mathrm{T}}\end{array}$ \\
\hline Steffel 2016 & 0.131 & 0.082 & 47.2 & $\begin{array}{l}1.14[0.97, \\
1.34]^{\mathrm{T}}\end{array}$ \\
\hline Total $(95 \% \mathrm{CI})$ & & & 100 & $\begin{array}{l}1.18[1.06, \\
1.32]\end{array}$ \\
\hline
\end{tabular}

SE, standard error; $C I$, confidence interval. Reviewer Manager 5.3 was used to conduct the analysis. The figures are rounded by Review Manager. Heterogeneity: $\operatorname{tau}^{2}=0.00 ; \mathrm{chi}^{2}=1.78, d f=3 \quad(P=0.62)$; $I^{2}=0 \%$; test for overall effect: $Z=2.97(P=0.003)$. ${ }^{1}$ Obtained by taking the inverse of the adjusted hazard ratios of fracture risk with NOAC versus VKA reported by the source articles

Published online July 24, 2019 versus warfarin). As Fiordellisi et al. defined the reference group as NOAC users in their meta-analysis, the inverse of these hazard ratios should have been used. Interestingly, when we re-calculated the pooled estimate by using the inverse of these figures, the result would suggest an association between a higher risk of fractures and the use of VKA versus NOAC (Table 1).

Further, in Fiordellisi et al., the data for Lau et al. ${ }^{5}$ was derived from the unadjusted event counts, whereas for all other three studies, ${ }^{2-4}$ the adjusted data were used. It is important that the adjusted estimates for all studies are used when pooling the data, not only for consistency, but also for the robustness of the pooled estimate. When the adjusted estimates were used, the result would, again, suggest an association of a higher risk of fracture with VKA versus NOAC (Table 2).

Our findings contradict with Fiordellisi et al. and might raise questions on the validity of their results, and the foundation of the study conclusion regarding whether fracture risk should be considered when choosing an oral anticoagulant. We hope that the relevance of our findings would be considered by Fiordellisi and colleagues, and further work would be taken in addressing these issues. As such, the validity and the impact of the influential findings of the article would be greatly enhanced.

Table 2 Pooled Results for Vitamin K Antagonists (VKAs) Versus Non-vitamin K Antagonist Oral Anticoagulant (NOAC) When the Inverse of the Adjusted Estimates Are Used for All Studies

\begin{tabular}{|c|c|c|c|c|}
\hline $\begin{array}{l}\text { Study or } \\
\text { subgroup }\end{array}$ & $\begin{array}{l}\text { Log [result } \\
\text { estimates] }\end{array}$ & SE & $\begin{array}{l}\text { Weight } \\
(\%)\end{array}$ & $\begin{array}{l}\text { Result } \\
\text { estimates } \\
\text { IV, random } \\
95 \% \text { CI }\end{array}$ \\
\hline Lau 2017 & 0.967 & 0.280 & 13.0 & $\begin{array}{l}2.63[1.52 \\
4.55]^{1}\end{array}$ \\
\hline $\begin{array}{l}\text { Lucenteforte } \\
2017\end{array}$ & 0.039 & 0.272 & 13.5 & $\begin{array}{l}1.04[0.61, \\
1.77]^{2}\end{array}$ \\
\hline Norby 2017 & 0.182 & 0.088 & 36.3 & $\begin{array}{l}1.20[1.01 \\
1.43]^{2}\end{array}$ \\
\hline Steffel 2016 & 0.131 & 0.082 & 37.2 & $\begin{array}{l}1.14[0.97 \\
1.34]^{2}\end{array}$ \\
\hline Total $(95 \% \mathrm{CI})$ & & & 100 & $\begin{array}{l}1.28[1.01, \\
1.62]\end{array}$ \\
\hline
\end{tabular}

SE, standard error; CI, confidence interval. Reviewer Manager 5.3 was used to conduct the analysis. The figures are rounded by Review Manager. Heterogeneity: $\operatorname{tau}^{2}=0.03 ; \operatorname{chi}^{2}=8.53, d f=3 \quad(P=0.04)$; $I^{2}=65 \%$; test for overall effect: $Z=2.06(P=0.04)$. ${ }^{I}$ Obtained by taking the inverse of the adjusted incidence rate ratio of fracture risk with NOAC versus warfarin reported by the source article. ${ }^{2}$ Obtained by taking the inverse of the adjusted hazard ratios of fracture risk with NOAC versus warfarin reported by the source articles 
Corresponding Author: Wallis C. Y. Lau, PhD; Research Department of Practice and Policy, UCL School of Pharmacy, London, UK (e-mail: wallis.lau@ucl.ac.uk).

\section{Compliance with Ethical Standards:}

Conflict of Interest: ICKW has received research funding outside the submitted work from the Hong Kong Research Grants Council, the Hong Kong Health and Medical Research Fund, Bristol-Myers Squibb, Pfizer, Janssen, and Bayer; KKCM is supported by the CW Maplethorpe Fellowship and has received personal fees outside the submitted work from IQVIA Holdings. No other disclosures were reported.

\section{REFERENCES}

1. Fiordellisi W, White K, Schweizer M. A Systematic Review and Metaanalysis of the Association Between Vitamin $\mathrm{K}$ Antagonist Use and
Fracture. J Gen Intern Med. 2018. https://doi.org/10.1007/s11606018-4758-2

2. Lucenteforte E, Bettiol A, Lombardi N, Mugelli A, Vannacci A. Risk of bone fractures among users of oral anticoagulants: An administrative database cohort study. Eur J Intern Med. 2017;44:e30-e1.

3. Norby FL, Bengtson LGS, Lutsey PL, Chen LY, MacLehose RF, Chamberlain AM, et al. Comparative effectiveness of rivaroxaban versus warfarin or dabigatran for the treatment of patients with non-valvular atrial fibrillation. BMC Cardiovasc Disord. 2017;17(1).

4. Steffel J, Giugliano RP, Braunwald E, Murphy SA, Mercuri M, Choi Y, et al. Edoxaban Versus Warfarin in Atrial Fibrillation Patients at Risk of Falling: ENGAGE AF-TIMI 48 Analysis. J Am Coll Cardiol. 2016;68(11):1169-78.

5. Lau WC, Chan EW, Cheung CL, Sing CW, Man KK, Lip GY, et al. Association Between Dabigatran vs Warfarin and Risk of Osteoporotic Fractures Among Patients With Nonvalvular Atrial Fibrillation. JAMA. 2017;317(11):1151-8.

Publisher's Note Springer Nature remains neutral with regard to jurisdictional claims in published maps and institutional affiliations. 